\title{
Design of a Fused Filament Fabrication (FFF) 3D-Printer
}

\author{
A. O. Oluwajobi ${ }^{\mathrm{a}, *}$, F. O. Kolawole ${ }^{\mathrm{b}}$ \\ ${ }^{a}$ Department of Mechanical Engineering, Obafemi Awolowo University, Ile Ife, Osun State, NIGERIA. \\ ${ }^{b}$ Prototype Engineering Development Institude, Ilesa, Osun State, NIGERIA.
}

\begin{abstract}
A Fused Filament Fabrication (FFF) 3D-printer was designed, for fabrication by using in part locally sourced materials. The printer design was based on the Replicating Rapid Prototyper (RepRap) open source. The print volume of the printer is $200 \mathrm{~mm} \times 200 \mathrm{~mm} \times 300 \mathrm{~mm}$ and it uses the Melzi V2 printer control board, coupled with the Repetier-Host firmware. The designed 3D-printer consists of galvanized steel frame, stainless steel threaded rods and wooded supports. The Finite Element Method (FEM) analysis was carried out on critical supporting components. The results obtained for the stresses are below the yield strength of the materials and the displacements are within acceptable limits, for high precision machines. The total power required by the $3 D$-printer was evaluated to be $197.93 \mathrm{~W}$ and it utilizes two thermoplastic materials namely; the Polylactic Acid (PLA) and the Acrylonitrile Butadiene Styrene (ABS).
\end{abstract}

Keywords: fused filament fabrication (FFF), low cost 3-D printer, polylactic acid (PLA) filament, acrylonitrile butadiene styrene (ABS) filament

\section{INTRODUCTION}

Additive manufacturing (AM) or 3D printing is a process of making a three-dimensional solid object of virtually any shape from a digital model, in successive layers. 3D printing is considered distinct from traditional machining technique, which mostly rely on material removal methods, until the desired shape has been achieved (subtractive processes). The 3D printing technology is used for both prototyping and distributed manufacturing with applications in industrial design, automotive, architecture, construction, aerospace, military, civil engineering, dental and medical industries, biotech (human tissue replacement), fashion, footwear, jewelry, eyewear, education, geographic information systems, food, and many other fields [1]. The terms AM and 3-D printing are many times used interchangeably, but they are not the same. AM is broader, as it encompasses all the different AM processes, namely; vat photopolymerization, material jetting, binder jetting, material extrusion, power bed fusion, sheet lamination and direct energy deposition. Whereas, 3-D printing is more of a singular production of artifacts on a desktop printer, which is almost synonymous with the material extrusion FFF process [2].

AM first approached commercial viability in 1983 when Charles Hull invented stereolithography, enabling a 3D object to be printed from

${ }^{*}$ Corresponding author (Tel: +234 (0)703 031 5921))

Email addresses: j.oluwajobi@gmail.com (A. O. Oluwajobi), kolawolefidelis@gmail.com (F. O. Kolawole)
CAD data. In 1986, Hull co-founded 3D Systems, Inc., the first company to commercialize additive manufacturing technology with the stereolithography (SLA) apparatus [3]. To advance the developments of 3D-printers, many open sources have been created, namely; Fab@Home, Ultimaker, RepRap et cetera. However, the RepRep [4] is the most famous and the most successful [5]. The RepRep was created by Adrian Bayer at the University of Bath in 2005. It was an initiative to develop 3D printers that could print most of their own components and to allow anyone to build, modify and improve them further. RepRap uses a variant of Fused Deposition Modeling (FDM), and called it Fused Filament Fabrication (FFF), to avoid trademark issues around the "FDM" term. As an open design, all the designs produced by the project are released under a free software license, the GNU General Public License.

In recent times, there have been interests in 3-D printing in Nigeria, both among the academics [610], and in the industry (General Electric, Nigeria). There are already initiatives to fabricate $3 \mathrm{D}$ printers locally $[6,10]$, and this should be further encouraged. Balogun et al. [6] developed a 3D printer with over 50\% locally sourced materials. They also investigated the impact of $3 \mathrm{D}$ printing technology on the Nigerian manufacturing GDP. The printer was estimated to cost about 500000 Naira. Farayibi and Abioye [9] conducted a survey to assess the awareness of AM technology in the South West Nigeria. They found out that there was about $40 \%$ in the level of awareness. Farayibi et al. [10] also developed a 3D printer using local 
materials. The printer has a maximum print volume of $200 \mathrm{~mm} \times 200 \mathrm{~mm} \times 200 \mathrm{~mm}$. The machine was designed among other things to be low cost, but this was not justified. The cost of the reported $3 \mathrm{D}$ printers is still high and the intention of this study is to reduce the cost considerably to under 200000 Naira, for entry level configurations. The goal is to design a FFF 3D printer, to be locally fabricated, rather than depending on the importation of the machines.

The adaptation of the 3D-printing has the potential to improve the manufacturing sector in Nigeria. In view of this, there is need for more active local development of the technology in Nigeria, to advance the capabilities of 3-D printing technologies and also to take full advantage of the benefits. This work involved the determination of displacements and stresses in supporting components of the FFF machine and the evaluation of the overall power requirement of the electrical components.

\section{THE FUNDAMENTALS OF THE FFF 3D PRINTING}

For the FFF 3D printer, a thermoplastic material is pushed through a nozzle under constant pressure and heated, then the extruded melt flow will deposit layer by layer to produce the $3 \mathrm{D}$ artefact [11].

\subsection{The FFF Process Steps}

The 3-D (FFF) printing process (Fig. 1) involves the creation of the part to be made, using a CAD software system. The CAD file is then converted to a stereolithographic (STL) file. Next, the STL file is converted to G codes, by using a suitable software. This STL file would then be uploaded to the 3-D printer, for 'printing' [12]. The FFF $3 \mathrm{D}$ printer builds objects from plastics using the extrusion process. The plastic filament is heated and extruded from a nozzle-like precise hot glue gun, while the machine prints out 3D objects, layer by layer. As one layer of plastic is laid on top of another, they fuse together, and, when cooled, form a solid and durable plastic part.

\subsection{The Governing Equation}

The general governing equation is given by Eq. (1);

$$
L(\varphi)+f=0
$$

and the boundary condition is given by Eq. (2);

$$
B(\varphi)+g=0
$$

where the parameters have usual notations.

The governing equation is converted into a matrix form, Eq. (3), by using the FEM;

$$
[K] u=F
$$

$K$ is the stiffness, $u$ is the displacement and $F$ is the force The solution is given in terms of the displacement in Eq. (4)

$$
u=[K]^{-1} F
$$

The above equations are implemented in the FEM software to obtain the solution of the displacements, and subsequently, the stress values are evaluated by using the constitutive equations.

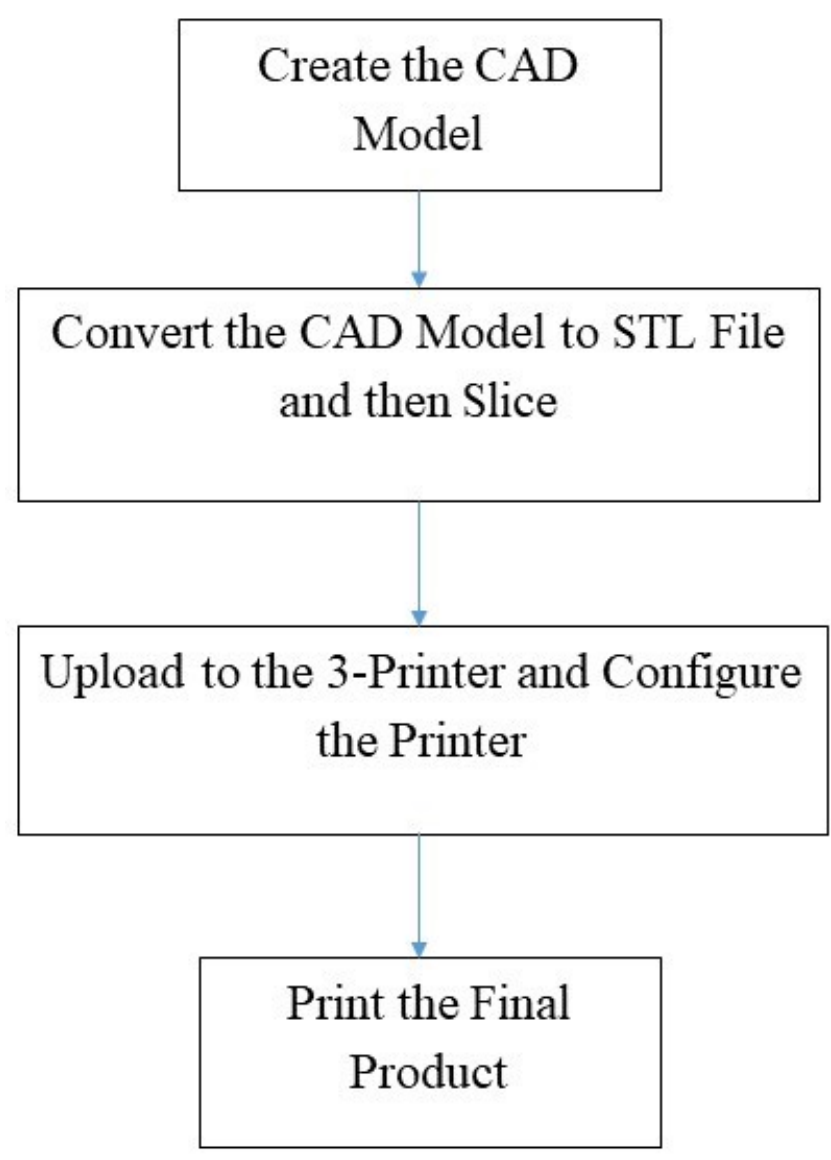

Figure 1: The FFF Process.

\section{METHODOLOGY}

\subsection{Design of the FFF Machine}

The printer consists of a main support plate which acts as the centre frame with three major motion axes ( $\mathrm{x}, \mathrm{y}$ and $\mathrm{z}$ ). The $\mathrm{x}$-carriage consists of two $\phi 8 \mathrm{~mm}$ stainless steel stud of length $370 \mathrm{~mm}$ each, two printed idlers A and B, a stepper motor, two z-nuts, a stepper motor pulley, a belt pulley and four $\phi 8 \mathrm{~mm}$ linear bearings. The printer's bottom plate is mounted on the y-carriage smooth rods. The y-carriage has one degree of freedom and it can move between the front and the back of the frame. The printer bottom plate is controlled by a belt attached to a stepper motor with pulley. The bottom plate has three linear bearings attached, that have been screwed to the print bottom plate. The z-axis consists of two plain studs and two lead screws attached to the stepper motors. This arrangement results in the upward and downward movement of the entire $\mathrm{x}$-carriage. The following considerations were employed in the design of the machine, namely; use of wood as a substitute for injection molded plastic parts, print volume of dimensions $(200 \mathrm{~mm} \times 200 \mathrm{~mm} \times 300$ $\mathrm{mm}$ ), ease of assembly, portability, low cost and overall rigidity of the frame. 


\subsubsection{The frame}

The frame is the printer's main component, on which other axes are mounted and it also gives the printer its rigidity and balance. The three axes (x, $\mathrm{y}$ and $\mathrm{z}$ ) of the printer are mounted on this frame. The frame was made from a $1.2 \mathrm{~mm}$ thick galvanized steel consisting of a main sheet and two support brace sheets, the main sheet is of dimension $400 \mathrm{~mm} \times 392 \mathrm{~mm}$ with and internal cut of 264.5 $\mathrm{mm} \times 306.25 \mathrm{~mm}$ to allow for easy travel of the print bed. Also, holes of $\phi 4 \mathrm{~mm}$ were drilled at pre-defined points, for fastening the wooden motor holders and support brace sheet to the main sheet.

\subsection{2. $X$ and $Y$-axes stepper motor drive force}

The drive force and the linear minimum displacement of the extruder are given by the following equations.

$$
F_{x}=\frac{C_{m}}{r}
$$

and

$$
S=\alpha_{p} \cdot r
$$

Where $\alpha_{p}$ is the stepper angle, $r$ is the pulley radius, $C_{m}$ is the stepper torque, $S$ is the minimum movement, $F_{x}$ is the drive force, $M$ is the stepper motor and $I$ is the ldler belt.

The NEMA 17 stepper motor has a torque of $0.55 \mathrm{Nm}$, pulley radius of $8 \mathrm{~mm}$ and a stepper angle of $1.8^{\circ}$. The drive force and the minimum displacement were calculated as:

$$
\begin{aligned}
& F_{x}=\frac{C_{m}}{r} \\
& F_{x}=\frac{0.55}{8} \times 1000=68.75 \mathrm{~N}
\end{aligned}
$$

and

$$
\begin{aligned}
S & =\alpha_{P} \cdot r \\
S & =1.8 \times \frac{\pi}{180} \times 8=0.25 \mathrm{~mm}
\end{aligned}
$$

\subsubsection{Belt length on $x$-axis}

The total length of the timing belt used on the drive mechanism on the x-axis to move the extruder sub-assembly, may be calculated using the following equation.

$$
L=2 C+\frac{\Pi\left(D_{1}+D_{2}\right)}{2}+\frac{\left(D_{2}+D_{1}\right)^{2}}{4 C}
$$

Where: $L$ is the total belt length in $\mathrm{mm}, C$ is the distance between shafts (in $\mathrm{mm}$ ) obtained from the CAD drawing, $D_{1}$ is the motor pulley in $\mathrm{mm}$ and $D_{2}$ is the ldler pulley in $\mathrm{mm}$.

Therefore,

$$
\begin{aligned}
& L=2 \times 392+\frac{\Pi(16+16)}{2}+\frac{(16-16)^{2}}{4 \times 392} \\
& L=834.26 \mathrm{~mm}
\end{aligned}
$$

\subsubsection{Belt length on $y$-axis}

The total timing belt length used on the drive mechanism (the y-axis) was also calculated as:

$$
\begin{aligned}
& L=2 \times 410+\frac{\pi(16+16)}{2}+\frac{(16-16)^{2}}{4 \times 410} \\
& L=870.24 \mathrm{~mm}
\end{aligned}
$$

\subsection{5. $X$-axis force analysis}

The maximum force exerted by the extruder on the rod was obtained from the CAD model, the yield strength and the ultimate tensile strength of stainless steel was obtained from the Autodesk Inventor 2015 software program style material. The maximum stresses on the plain rod will occur at the mid-point. Therefore, the minimum and maximum bending stresses on the $\mathrm{x}$-axis plain rod were calculated with the following equation.

$$
S_{\max }=\frac{M_{\max } C}{I}
$$

Where the maximum bending moment is given as

$$
\begin{aligned}
M_{\max } & =F(X) \\
M_{\max } & =5.317(0.187)=0.994 N m \\
S_{\max } & =\frac{(0.994)\left(\frac{0.008}{2}\right)}{\left(\Pi \frac{0.008^{4}}{64}\right)}=19.78 \mathrm{MPa}
\end{aligned}
$$

\subsubsection{Z-axis force analysis}

The most stressed positional configuration of the z-axis plain rods assembly was considered (i.e. when the $\mathrm{x}$-axis carriage is at the top most position). An axial force and a bending force exist at this point. The maximum values of the axial force obtained from the CAD model was $10.644 \mathrm{~N}$ and the maximum value of the axial stress was calculated to be;

$$
S_{\max }=\frac{10.644}{\left(\Pi \frac{0.008^{2}}{4}\right)}=0.199 \mathrm{MPa}
$$

The maximum bending stresses was calculated

$$
S_{\text {max }}=\frac{(0.199)\left(\frac{0.008}{2}\right)}{\left(\Pi \frac{0.008^{4}}{64}\right)}=3.96 M P a
$$

\subsection{Materials Selection and Consideration}

The materials selected for the component parts, and the justifications are shown in Table 1 . The consideration is to have an overall low cost, availability of local materials and the ability to $3 \mathrm{D}$ print many component parts. Many parts are available in the local market, as seen in Table 1 and some other are to be imported from China. The $\mathrm{X}$ and $\mathrm{Y}$ motor holders, the $\mathrm{Y}$ brace and the extruder motor holder are to be 3D printed, using the PLA filament material. 
Table 1: Materials Selection for the FFF Machine.

\begin{tabular}{|c|c|c|c|c|}
\hline $\mathbf{S} / \mathbf{N}$ & Machine Components & Material Selected & Justification & Source \\
\hline 1 & Threaded and Plain Rods & Stainless Steel & $\begin{array}{l}\text { Rigidity and resistance } \\
\text { to corrosion }\end{array}$ & Local \\
\hline 2 & Support Sheet Frame & Galvanized Steel & $\begin{array}{l}\text { Availability, workability } \\
\text { and resistance to corrosion }\end{array}$ & Local \\
\hline 3 & $\begin{array}{l}\text { Base Corner Pieces } \\
\text { and Z-Motor Holders }\end{array}$ & Wood & $\begin{array}{l}\text { Availability and ease } \\
\text { of machining to achieve } \\
\text { desired shape }\end{array}$ & Local \\
\hline 4 & $\begin{array}{l}\text { X-Motor, Y-Motor Holder Carriers, } \\
\text { Idlers and Extruder Motor Holder }\end{array}$ & PLA - 3D Printed & $\begin{array}{l}\text { Strength and high } \\
\text { thermal resistance }\end{array}$ & Local \\
\hline 5 & Linear Bearings and Pulleys & Aluminum 6061 & $\begin{array}{l}\text { Light weight and } \\
\text { availability }\end{array}$ & Imported \\
\hline 6 & GT2 Belt driver & Rubber & $\begin{array}{l}\text { Light weight and } \\
\text { low cost }\end{array}$ & Imported \\
\hline 7 & Stepper Motors & NEMA 17 Stepper Motors & $\begin{array}{l}\text { Capability for the required } \\
\text { torque to drive the axes }\end{array}$ & Imported \\
\hline 8 & Bolts, Nuts and Washers & Stainless Steel & $\begin{array}{l}\text { Availability and resistance } \\
\text { to corrosion }\end{array}$ & Local \\
\hline 9 & Control Board & Melzi 2.0 Control Board & $\begin{array}{l}\text { Portability and ease } \\
\text { of programming }\end{array}$ & Imported \\
\hline 10 & Extruder & Aluminum and PLA & $\begin{array}{l}\text { Good thermal conductivity } \\
\text { and heat distribution }\end{array}$ & Imported \\
\hline
\end{tabular}

\subsection{Electrical Power Requirement Calcula- tions}

To select an adequate power pack for the 3D printer, the electrical power consumption for all the standard electrical component parts was calculated using the following:

$$
\begin{gathered}
P=I V \\
P=\frac{V^{2}}{R} \\
P=I^{2} R
\end{gathered}
$$

\subsubsection{Power required by the extruder}

The extruder consists of a NEMA 17 stepper motor with a rated voltage of $4.7 \mathrm{~V}$ and current of $1.7 \mathrm{~A}$, a $12 \mathrm{~V} \mathrm{DC}$ cartridge heater rated $40 \mathrm{~W}$ and a $12 \mathrm{~V} \mathrm{DC}$ fan with a current of $0.5 \mathrm{~A}$.

Power required by NEMA 17 stepper motor: $P=$ $1.7 \times 4.7=7.99 \mathrm{~W}$

Power required by the Fan: $P=0.06 \times 12=0.72 \mathrm{~W}$

Total power required by the extruder $=7.99+$ $0.72+40=48.71 \mathrm{~W}$

\subsubsection{Power required by the drive axes}

The 3D-printer consists of three drive axes with four stepper motors with a rated voltage of $4.7 \mathrm{~V}$ and current of $1.7 \mathrm{~A}$ each.

Total power required by the Stepper motors: $(7.99) \times 4=31.96 \mathrm{~W}$

\subsubsection{Power required by the heat bed}

The heat bed used on the FFF machine was rated $12 \mathrm{~V} \mathrm{DC}$ with a resistance of

\subsubsection{Power required by the heat bed}

$$
P=\frac{12^{2}}{1.4}=102.86 \mathrm{~W}
$$

\subsubsection{Power Required by the Control Board}

The FFF machine is controlled by a Melzi V2 board powered from $12 \mathrm{~V}$ DC which is then regulated down to $5 \mathrm{~V}$ by a 7805 linear regulator.

Power required by the Control Board: $P=12 \times$ $1.2=14.4 \mathrm{~W}$

The total power required by $\mathrm{FFF}$ machine is therefore $197.93 \mathrm{~W}$. A 12V DC ATX power supply with a current rating of $30 \mathrm{~A}(360 \mathrm{~W})$ was chosen to power the FFF machine with enough tolerance for future expansion.

\subsection{Axes Movement Calculations}

The firmware used on the FFF machine is based on the custom built Repetier firmware editor and it was further re-edited using Arduino IDE, to obtain optimum performance and the calibration of the machine. The stepper motors used have the following specifications and they were employed in the calculation of the axes movements.

Stepper Motor Name $=$ NEMA 17, Step Angle $=$ $1.8^{\circ}$, Micro Stepping $=1 / 16$, Timing-belt Pitch $=2$ $\mathrm{mm}$, Motor Pulley Teeth $=20$, Leadscrew Pitch $=$ $8 \mathrm{~mm}$, and Pinch Wheel Diameter $=7.5 \mathrm{~mm}$.

$$
X_{\text {axis }}=\frac{\text { motor steps per rev } \times \frac{1}{\text { microstepping }}}{\text { belt pitch } \times \text { motor pulley teeth }}
$$

$$
=\frac{\text { motor steps per rev } \times \frac{1}{\text { microstepping }}}{\text { belt pitch } \times \text { motor pulley teeth }}
$$

$$
Z_{\text {axis }}=\frac{\text { motor steps per rev } \times \frac{1}{\text { microstepping }}}{\text { leadscrew pitch } \times \text { gear ratio }}
$$


$E_{\text {motor }}=$ motor steps per rev $\times \frac{1}{\text { microstepping }} \times$ gear ratio pitch wheel diameter $\times \Pi$

Motor step/rev $=\frac{360}{1.8}=200 ; X_{\text {axis }}=\frac{200 \times 16}{2 \times 20}=$ 80 steps $/ \mathrm{mm} ; \quad Y_{\text {axis }}=\frac{200 \times 16}{2 \times 20}=80$ steps $/ \mathrm{mm}$; $Z_{\text {axis }}=\frac{200 \times 16}{8 \times 1}=400$ steps $/ \mathrm{mm} ; E=\frac{200 \times 16 \times 1}{7.5 \times 3.14}=$ 135.88 steps $/ \mathrm{mm}$.

\subsection{X-Carriage Sub-Assembly}

The x-carriage consists of two $\phi 8 \mathrm{~mm}$ stainless steel stud of length $370 \mathrm{~mm}$, two printed idlers A and B, stepper motor (NEMA 17), stepper motor pulley, GT2 timing-belt and four $\phi 8 \mathrm{~mm}$ linear bearings. Idler A and B are the two major components of the x-axis upon which all other components are to be assembled.

\subsubsection{Idler A}

The idler A was designed with two hollow cylindrical attachments with a centre-to-centre distance of $20 \mathrm{~mm}$ to hold two linear bearings and a lead screw nut in alignment of the z-axis, a back mount for the x-axis stepper motor and an internal cut for the GT2 timing-belt to transmit rotary motion from the stepper motor pulley to the linear motion of the extruder sub-assembly. A FEM analysis was carried out on the Idler A, which carries the stepper motor that controls the y-axis by using the Autodesk Simulation Mechanical (ASM) software. The analysis considered the force and the moment generated by the extruder sub-assembly, the stepper motor weight and the holding torque.

\subsubsection{Idler $B$}

The idler B was designed with two hollow cylindrical attachments with a centre-to-centre distance of $20 \mathrm{~mm}$ to hold two linear bearings and a lead screw nut in alignment with the z-axis and an internal cut for the GT2 timing-belt to transmit rotary motion from the stepper motor pulley around a $608 \mathrm{Z}$ flange bearing to the linear motion of the extruder sub-assembly.

The X-carriage sub-assembly parts are shown in Table 2.

\subsection{Y-carriage sub-assembly}

The y-carriage sub-assembly allows the print bottom plate one degree of freedom during the printing operation. The y-carriage would be made from two $\phi 8 \mathrm{~mm}$ plain stainless steel rods, two M8 $\times 1.25 \mathrm{~mm}$ threaded stainless steel rods along the print bottom axis of travel and four stainless steel M8 $\times 1.25 \mathrm{~mm}$ along the travel axis of the extruder for bracing, a Y brace motor holder for the print bottom plate travel and four y-corners to be shaped out of wood. This would also act as the sub-assembly bracing as well base for the entire assembly.
Table 2: X-Carriage Sub-Assembly Parts and Specifications.

\begin{tabular}{lll}
\hline S/N & Parts & Description \\
\hline 1 & Idler A & $90 \mathrm{~mm} \times 35.75 \mathrm{~mm} \times 67 \mathrm{~mm}$ \\
2 & Idler B & $45 \mathrm{~mm} \times 35.75 \mathrm{~mm} \times 67 \mathrm{~mm}$ \\
3 & Linear bearing & LM 8UU \\
4 & Plain rods & $\phi 8 \mathrm{~mm} \times 370 \mathrm{~mm}$ \\
5 & Z-nut & $\phi 8 \mathrm{~mm}$ \\
6 & Stepper motor & NEMA 17 \\
7 & Timing-Belt & GT 2 \\
8 & Motor pulley & $\phi 6 \mathrm{~mm}$ \\
9 & Belt idler & $\phi 6 \mathrm{~mm}$ \\
10 & Bolts & $\mathrm{M} 3$ \\
11 & Washers & $3 \mathrm{~mm}$ \\
\hline
\end{tabular}

Table 3: Y-Carriage Sub-Assembly Parts with Specifications.

\begin{tabular}{lll}
\hline S/N & Parts & Description \\
\hline 1 & Y-Corners & $20 \mathrm{~mm} \times 20 \mathrm{~mm} \times 65 \mathrm{~mm}$ \\
2 & Plain rods & $\phi 8 \mathrm{~mm} \times 461.8 \mathrm{~mm}$ \\
3 & Threaded rods & $\phi 8 \mathrm{~mm} \times 370 \mathrm{~mm}$ \\
4 & Stepper motor & NEMA 17 \\
5 & Linear Bearing & SC8UU \\
& with Housing & M8 \\
6 & Nuts & $8 \mathrm{~mm}$ \\
7 & Washers & M3 $\times 12 \mathrm{~mm}$ \\
8 & Nuts & M3 \\
9 & Bolts & $\phi 3$ \\
10 & Washers & $\phi 18$ \\
11 & Motor Pulley & - \\
12 & Y brace motor holder & \\
\hline
\end{tabular}

\subsubsection{The Y brace Motor Holder}

The Y brace motor holder was designed on the Autodesk Inventor software, so as to fit between the M8 $\times 1.25 \mathrm{~mm}$ bracing the y-corners. The y-axis stepper motor with the pulley would be mounted on the Y brace motor holder with three M3 bolts, to translate the rotary motion of the motor to the linear motion of the print bed subassembly. A FEM analysis was carried out on the $\mathrm{Y}$ brace during the design using the ASM software.

\subsubsection{The y-corner support}

The y-corner support is of dimensions $20 \mathrm{~mm} \times$ $20 \mathrm{~mm} \times 65 \mathrm{~mm}$ and would be made from a hard seasoned wood (Oak). Two holes with centre-tocentre distance of $30 \mathrm{~mm}$ would be drilled along the $\mathrm{x}$-axis of the $\mathrm{y}$-corners, for bracing and to the Y brace stepper motor carrier. Another set of holes with centre-to-centre distance of $30 \mathrm{~mm}$ would be drilled along the y-axis for the print bottom plate plain rods and the thread rods for bracing.

The Y-carriage sub-assembly parts are shown in Table 3

\subsubsection{Z-Carriage Sub-Assembly}

The z-axis consists of two $\phi 8 \mathrm{~mm} \times 356 \mathrm{~mm}$ stainless steel plain rods, two M8 $\times 8 \mathrm{~mm} \times 300$ $\mathrm{mm}$ stainless steel lead screws attached to the axis stepper motors, two $\phi 8 \mathrm{~mm}$ linear coupling, 
two z-rod holders and two stepper motor holders to be shaped out of wood. The two stepper motors on the z-axis transmit motion simultaneously to the lead screws via the linear coupling and the two plain stainless steel rods serves as guides for the upward and downward of the entire $\mathrm{x}$-carriage sub-assembly. The Z-carriage sub-assembly parts are shown in Table 4.

Table 4: Z-Carriage Sub-Assembly Parts with Specifications.

\begin{tabular}{lll}
\hline S/N & Parts & Description \\
\hline 1 & Stainless steel plain rods & $\phi 8 \mathrm{~mm} \times 356 \mathrm{~mm}$ \\
2 & Stepper motor & NEMA 17 \\
3 & Lead screws & M8 $\times 8 \mathrm{~mm} \times 300 \mathrm{~mm}$ \\
4 & Linear coupling & $\phi 8 \mathrm{~mm}$ \\
5 & Linear bearing & LM8UU \\
6 & Nuts & M4 $\times 10 \mathrm{~mm}$ \\
7 & Bolts & M4 \\
8 & Washers & $\phi 4$ \\
9 & Nuts & $\mathrm{M} 3 \times 12 \mathrm{~mm}$ \\
10 & Bolts & $\mathrm{M} 3$ \\
11 & Motor pulley & $\phi 18$ \\
12 & Motor holders & - \\
13 & Z-Rod holders & - \\
\hline
\end{tabular}

\subsection{Motor Holders and Z-Rod Holders}

The motor holders and the z-rod holders have similar shapes and they perform similar functions on the z-axis sub-assembly of the $3 \mathrm{D}$ printer. Both holders would be made from Oak. The stepper motors would be fitted to the motor holders with three M3 bolts and the sub-assembly would be fitted to the printer sheet metal frame using two M4 bolts and nuts. The z-rod holders would also be fitted to the sheet metal frame with two M4 bolts and nuts keeping the stainless steel plain rod in alignment with the hole on the lower motor holders.

\subsection{Print Bed Sub-Assembly}

The print bed sub-assembly serves as the platform upon which parts to be printed with the 3D printer, are layered. The print bed consists of three main component parts; the base plate, the heat bed and the print glass. The base plate would be constructed from a $220 \mathrm{~mm} \times 220 \mathrm{~mm} \times 3 \mathrm{~mm}$ stainless steel plate, three sets of mounting holes $\phi 4 \mathrm{~mm}$ with centre-to-centre distance of $80 \mathrm{~mm}$ (corresponding to the distance between the plain stainless steel rods on the y-axis sub-assembly) would be drilled on the plate. The heat bed would be made from a $214 \mathrm{~mm} \times 214 \mathrm{~mm} \times 2 \mathrm{~mm}$ copper clad PCB board routed with a CNC PCB routing machine to achieve the desired temperature when voltage is passed through the terminals during printing operation. The print glass would be cut from a $205 \mathrm{~mm} \times 205 \mathrm{~mm} \times 3 \mathrm{~mm}$ heat tempered transparent glass, this the parts to be printed in the machine flawless surface with zero gradient. The print bed component parts are shown in Table 5.
Table 5: Print Bed Component Parts with Specifications.

\begin{tabular}{lll}
\hline S/N & Parts & Description \\
\hline 1 & Base plate & $220 \mathrm{~mm} \times 220 \mathrm{~mm} \times 3 \mathrm{~mm}$ \\
2 & Heat bed & $214 \mathrm{~mm} \times 214 \mathrm{~mm} \times 2 \mathrm{~mm}$ \\
3 & Print glass & $205 \mathrm{~mm} \times 205 \mathrm{~mm} \times 3 \mathrm{~mm}$ \\
4 & Bolts & M3 $\times 20 \mathrm{~mm}$ \\
5 & Nuts & M3 \\
6 & Spring inner & $\phi 4 \mathrm{~mm}$ \\
\hline
\end{tabular}

\subsection{Extruder}

The extruder controls the precise deposition on the print bed during the printing operation. It is divided into two main sub-assemblies, the filament drive and the thermal hot end. The filament drive pulls in plastic filament, (often bundled in spools of either $3 \mathrm{~mm}$ or $1.75 \mathrm{~mm}$ diameter) by using a geared driver mechanism. This consists of the extruder stepper motor carrier, filament clip A, filament clip B, stepper motor, extruder gear (pinch wheel), and a compression spring. The thermal hot end consists of an aluminum block of $15 \mathrm{~mm} \times 15 \mathrm{~mm} \times 10 \mathrm{~mm}$ with an embedded

$12 \mathrm{~V}$ DC heater. It also has a temperature sensor and a polyether ether ketone (PEEK) barrel which thermally insulate the hot end from the rest of the extruder

\subsubsection{Extruder motor carrier}

The extruder motor carrier serves as the base component of the extruder on which other components of the extruder is assembled. The motor carrier was designed on the Autodesk Inventor Professional (AIP) software.

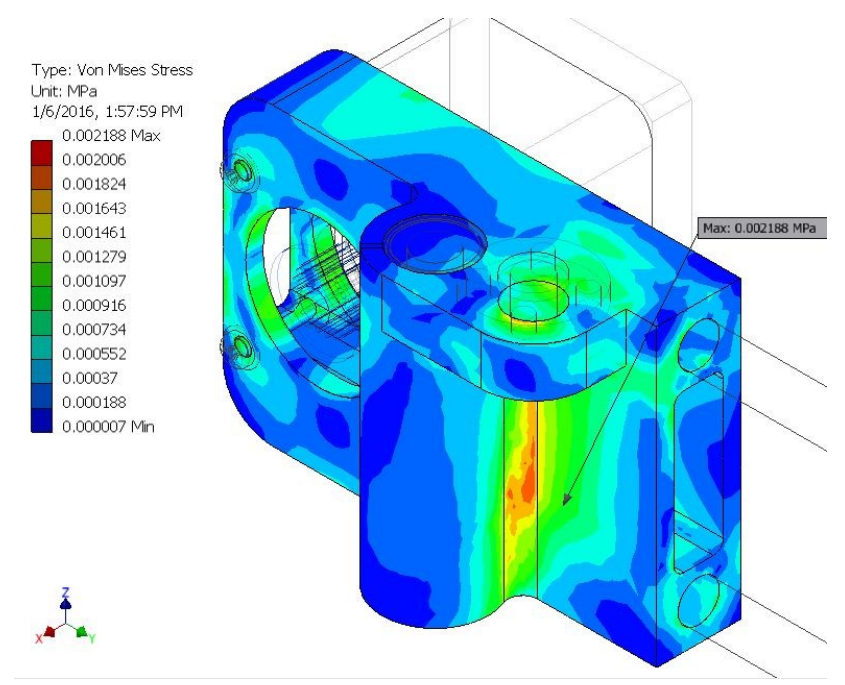

Figure 2: Idler A showing FEA analysis of Von Mises Stress.

\subsubsection{The hot end}

The hot-end has three crucial components namely; a thermistor to measure the temperature, a heat barrier which separates the hot end from the cold end (PEEK barrel) and the nozzle where 
Table 6: Polylactic Acid (PLA) - Biopolymer (Material Data Sheet) [13].

\begin{tabular}{llll}
\hline Properties & Minimum & Maximum & Average \\
Modulus of Elasticity & $0.085 \mathrm{GPa}$ & $13.8 \mathrm{GPa}$ & $2.91 \mathrm{GPa}$ \\
Yield Tensile Strength & $2.00 \mathrm{MPa}$ & $103 \mathrm{MPa}$ & $38 \mathrm{MPa}$ \\
Ultimate Tensile Strength & $14.0 \mathrm{MPa}$ & $117 \mathrm{MPa}$ & $47.2 \mathrm{MPaK}$ \\
\hline
\end{tabular}

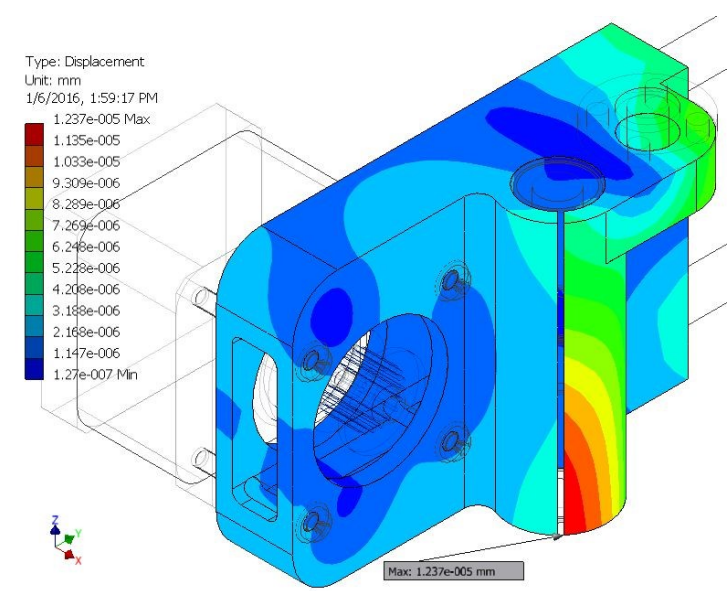

Figure 3: Idler A showing FEA analysis of Displacement.

the melted plastic flows out of the heater barrel. The hot end aluminum block would be machined to $15 \mathrm{~mm} \times 15 \mathrm{~mm} \times 10 \mathrm{~mm}$ on a table top milling machine; a fitting hole of $\phi 3.5 \mathrm{~mm}$ would be drilled and tapped to M4 $\times 0.7 \mathrm{~mm}$. Two holes of $\phi 6 \mathrm{~mm}$ and $\phi 2 \mathrm{~mm}$ respectively would be drilled on the side of the aluminum block to accommodate the $12 \mathrm{~V} \mathrm{DC}$ heater and the $100 \mathrm{k} \Omega$ temperature sensor. The PEEK barrel, the heater and the temperature sensor would then be fitted to the aluminum block to form the complete hot end assembly.

\subsection{Printer Control and Electronics}

The electronics to be used in the control of the 3D printer are standard modular comprise the microcontroller, main board, motor drivers, stepper motors, hot end, print bed, endstop or limit switches and temperature sensors.

\subsubsection{The control board}

The printer uses a standard Melzi V2.0 as the main control board with an ATMEGA 1284P $16 \mathrm{MHz}$ microcontroller, integrated USB chip FT232RL socket and an A4988 stepper driver

\subsection{D Printed Parts}

The PLA filament material would be used to print the $3 \mathrm{D}$ printed parts and the materials properties are shown in Table 6 . These parts include the idler $\mathrm{A}$ and $\mathrm{B}$, the $\mathrm{Y}$ brace and the extruder motor holder.

\subsection{Design Yield Factor of Safety}

The yield factor of safety was considered in the design, and it is given by Eq. (18).

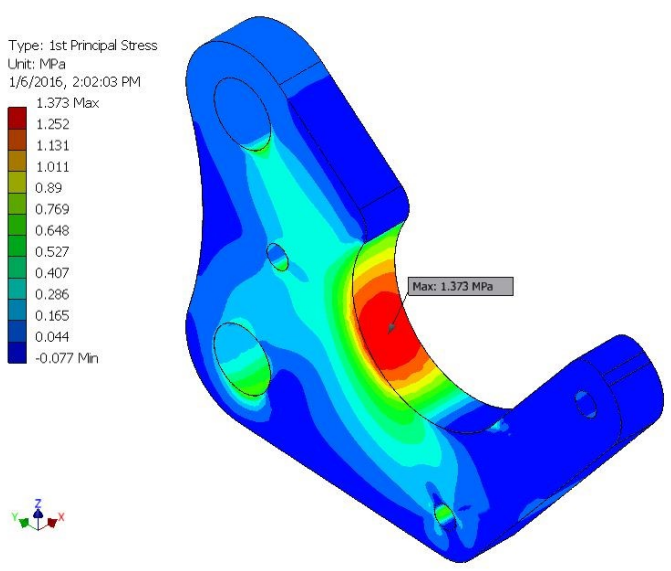

Figure 4: Y brace showing FEA results of 1st Principal Stress.

$$
\text { Yield factor of safety }=\frac{\text { Yield strenght }}{\text { Maximum stress }}
$$

When the factor of safety is greater less than 1 , the component part would definitely fail.

\section{RESULTS AND DISCUSSION}

Figures 2 and 3 show the von Mises stress and displacement results, for the idler $\mathrm{A}$. The maximum stress and displacement obtained from the FEA analysis are $0.002188 \mathrm{MPa}$ and $1.237 \times 10^{-5}$ $\mathrm{mm}$ respectively.

Figures 4 and 5 show the 1st principal stress (tension) and displacement results for the Y brace. The maximum stress and displacement obtained from the FEA results are $1.373 \mathrm{MPa}$ and 0.0415 $\mathrm{mm}$ respectively.

Figures 6 and 7 show the von Mises stress and the displacement results for the extruder motor holder. The maximum stress and displacement obtained from the FEM simulations are 5.16 $\mathrm{MPa}$ and $0.0543 \mathrm{~mm}$ respectively.

The maximum stress and the displacement values, obtained from the FEM simulations indicate areas where there could be likely failures, when the component parts are subjected to working loads. The average yield factor of safety values calculated for the Idler A, Y brace and the extruder holder are 17301, 28 and 7 respectively. The obtained high factors of safety reveal that the designed parts are over-designed [10] and would not likely fail during use and operation. The results obtained for the stresses are below the yield strength of the materials and the displacements are within acceptable limits, for high precision 


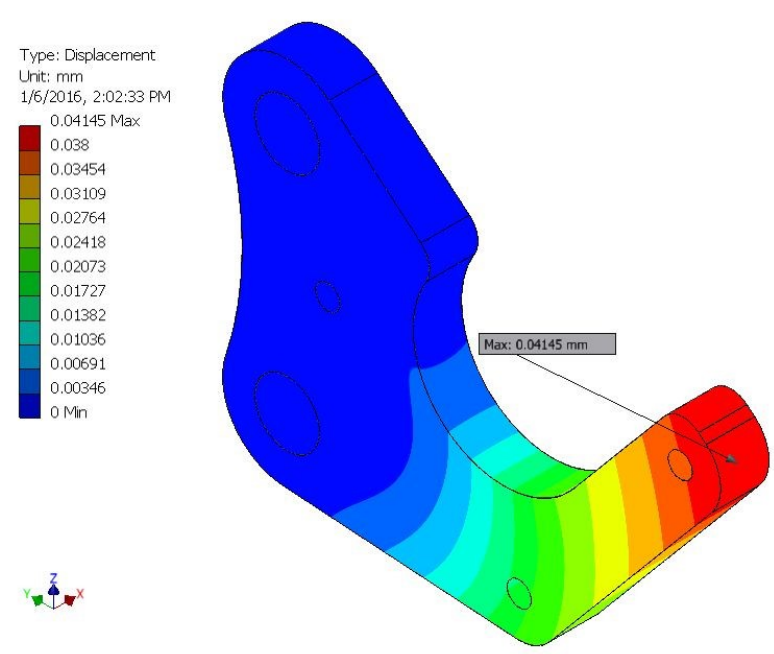

Figure 5: Y brace showing FEA results of Displacement.

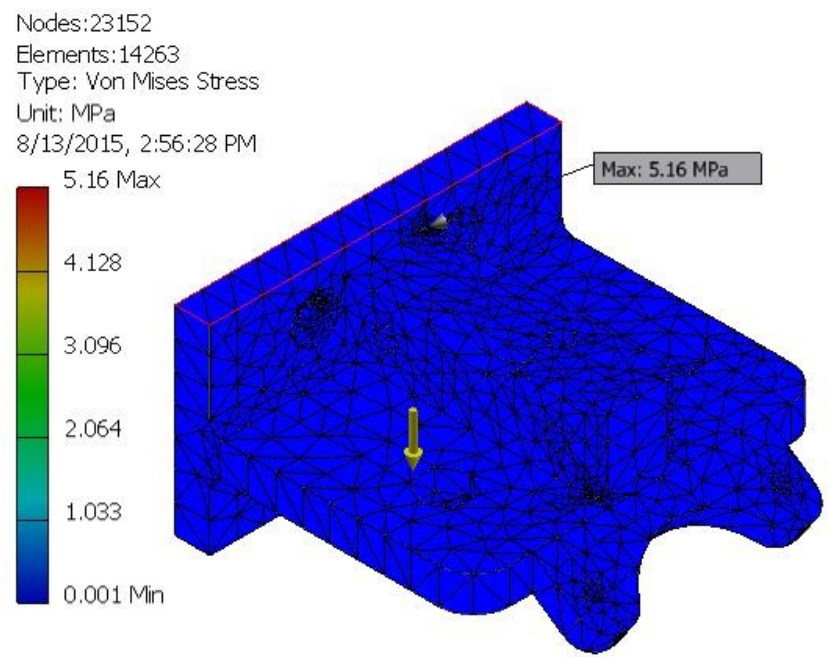

Figure 6: Extruder motor carrier showing FEA results of areas of high stress concentration.

machines. Figures 8 and 9 shows the CAD model of the complete assembly of the 3D-printer.

\section{CONCLUSION}

This study focused on the design of a low cost FFF 3D-printer. The FEM analyses were carried on some critical supporting components. The maximum stress and the maximum displacement values are viz; for the Idler A, the von Mises stress was $0.002188 \mathrm{MPa}$ and the displacement was $1.237 \times 10^{-5} \mathrm{~mm}$; for the Y brace motor holder, the von Mises stress was $1.373 \mathrm{MPa}$ and the displacement was $0.0415 \mathrm{~mm}$; for the extruder motor carrier, the von Mises stress was $5.16 \mathrm{MPa}$ and the displacement was $0.0543 \mathrm{~mm}$. These stress values are below the yield strength of the materials and the displacement values are within acceptable limits for high precision machines.

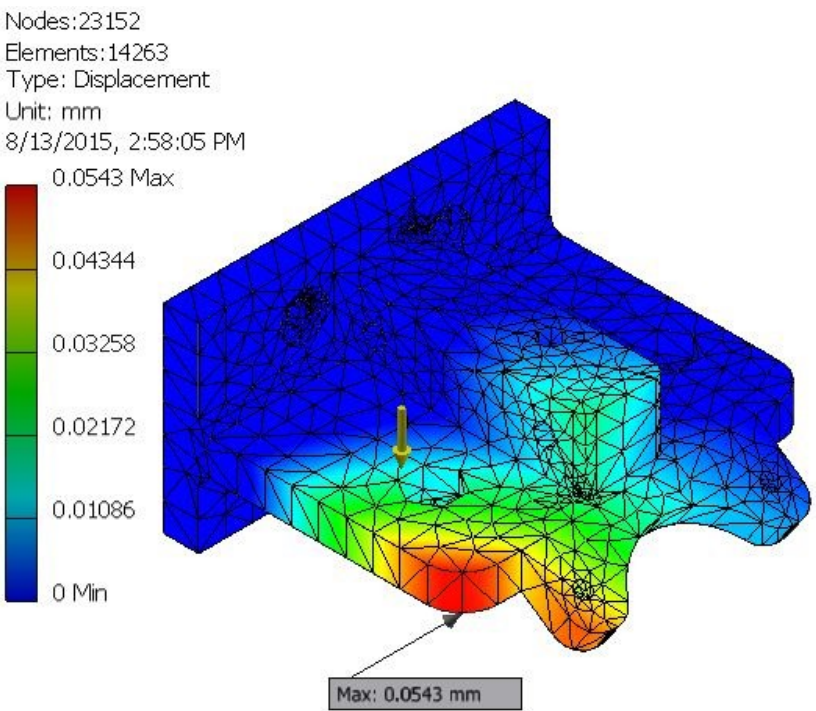

Figure 7: Extruder motor carrier showing FEA results of maximum displacement.

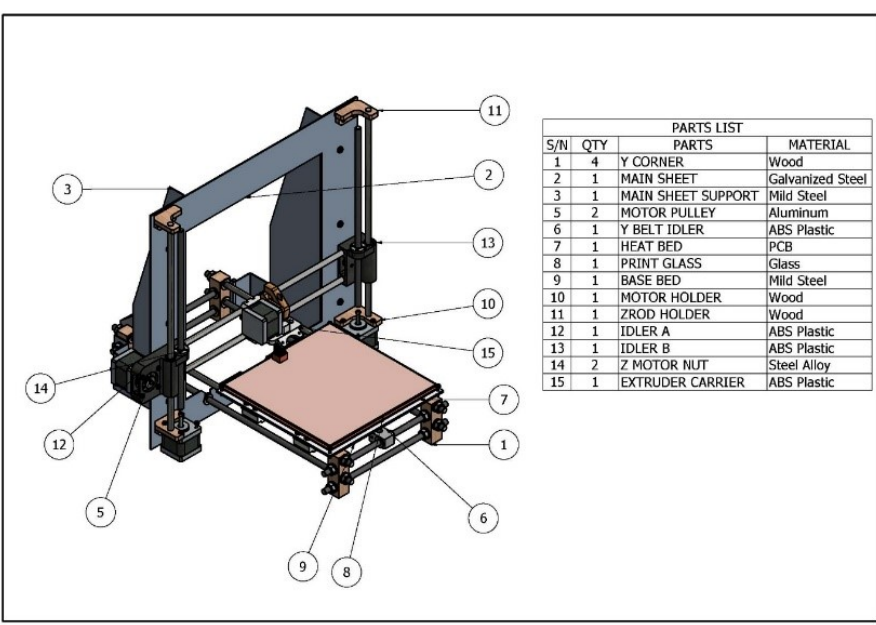

Figure 8: Completely assembled CAD model of the FFF machine.

\section{References}

[1] M. Cotteleer, J. Holdowsky, and M. Mahto, The 3D opportunity primer: The basics of additive manufacturing. Deloltte University Press, 2013.

[2] (2020, June) General electric. [Online]. Available: https://www.ge.com/additive/additivemanufacturing/information/3d-printing

[3] I. Gibson, W. David, and S. Brent, Additive Manufacturing Technologies: Rapid Prototyping to Direct Digital Manufacturing. New York: Springer, 2009.

[4] R. Jones, P. Haufe, E. Sells, P. Iravani, V. Olliver, C. Palmer, and A. Bowyer, "Reprap - the replicating rapid prototype," Robotica, vol. 29, no. 1, pp. 177-191, 2011.

[5] N. Rosli, M. R. Alkahari, F. Ramli, S. Maidin, M. Sudin, S. Subramoniam, and T. Furumoto, "Design and development of a low-cost 3D metal printer," Journal of Mechanical Engineering Research \& Developments, vol. 41, no. 3, pp. 47-54, 2018.

[6] V. Balogun, O. Otanocha, and A. Ibhadode, "The impact of 3D printing technology to the Nigerian manufacturing GDP," Modern Mechanical Engineering, vol. 8, no. 2, pp. 140-157, 2018.

[7] C. Nwaeche, A. O. Fagunwa, A. Olokoshe, A. Aderonmu, 

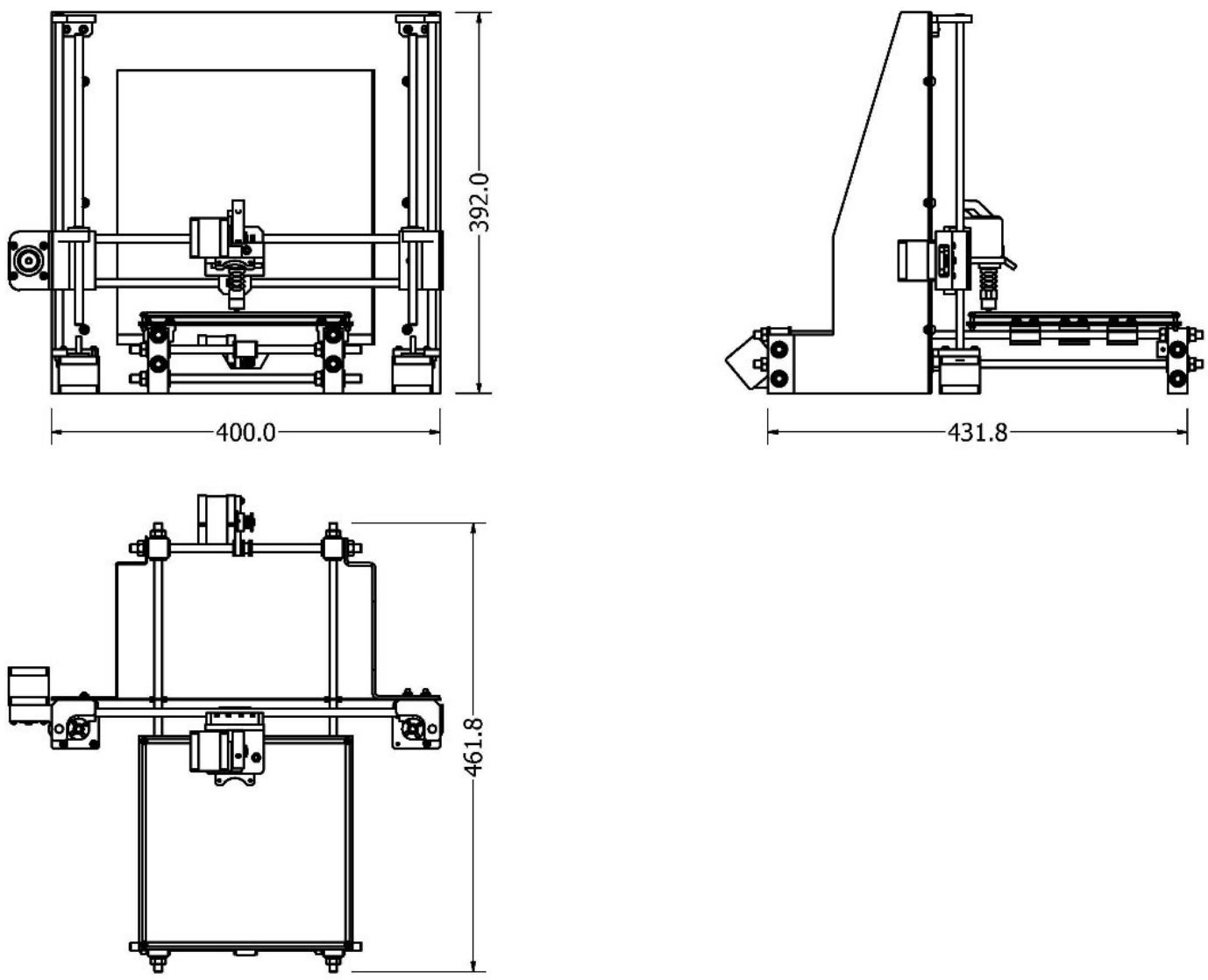

Figure 9: The views.

V. Uzondu, O. Salami, and W. Asiru, "Comparative Studies on Additive and Subtractive Manufacturing in Nigeria Case Study: Helical Gear in a Juice Extractor," Asian Journal of Advanced Research and Reports, vol. 7 , no. 3, pp. 1-11, 2019.

[8] T. Omole, A. Olaiya, O. Sanni, R. Freddy, S. Oluwasola, W. Djibril, O. Aturaka, O. Ajani, Z. Gwa, M. Abdulsalam, L. Ajani, and L. Olaide, "Additive Manufacturing/3D in the Optimization of Nigeria Vaccine Supply Chain," International Journal of Scientific and Research Publications, vol. 9, no. 11, pp. 261-267, 2019.

[9] P. Farayibi and T. Abioye, "A Study on the Awareness Level of Additive Manufacturing Technology in SouthWestern Nigeria," African Journal of Science, Technology, Innovation and Development, vol. 9, no. 2, pp. 157$62,2017$.

[10] P. Farayibi, J. Dioha, J. Orukotan, and B. Omiyale, "Development of a fused deposition modelling machine for plastic-based additive manufacturing purposes," $A s$ sumption University E-Journal of Interdisciplinary Research, vol. 4, no. 2, pp. 1-11, 2019.

[11] J. Lee, J. An, and C. Chua, "Development of a fused deposition modelling machine for plastic-based additive manufacturing purposes," Applied materials Today, vol. 7, pp. 120-133, 2017.

[12] J. Steuben, D. L. Van Bossuyt, and C. Turner, "Design for fused filament fabrication additive manufacturing," in ASME International Design Engineering Technical Conferences \& Computers and Information in Engineering Conference, 2015.

[13] (2020, August) Matweb Material Property Data, Polylactic Acid (PLA) - Biopolymer. [Online]. Available: http://www.matweb.com/search/DataSheet.aspx? MatGUID=ab96a4c0655c4018a8785ac4031b9278\& ckck $=1$ 